\title{
BUILDING CAPACITY IN FIELD EPIDEMIOLOGY: LESSONS LEARNED FROM THE EXPERIENCE IN EUROPE
}

\author{
H T Walke (hfw3@cdc.gov)1, P M Simone ${ }^{1}$ \\ 1. Division of Global Public Health Capacity Development, Coordinating Office for Global Health, Centers for Disease Control and \\ Prevention, Atlanta, United States
}

This article was published on 29 October 2009.

Citation style for this article: Walke HT, Simone PM. Building capacity in field epidemiology: lessons learned from the experience in Europe. Euro Surveill. 2009;14(43):pii=19376. Available online: http://www.eurosurveillance.org/ViewArticle.aspx?ArticleId=19376

This issue of Eurosurveillance is devoted to training of field epidemiologists within diverse public health systems and highlights the contributions these programmes are making in Europe. The articles describe national field epidemiology training programmes (FETPs) [1], the European Programme for Interventional Epidemiology Training (EPIET) [2] and its transition to the European Centre for Disease Prevention and Control (ECDC) [3], how ECDC through its training activities is contributing towards building capacity in surveillance and response in communicable diseases, as well as the strengths and challenges of the various models of applied epidemiology training [4].

FETPs are two-year training programmes in applied epidemiology, based on a model of 'learning by doing'. They build public health capacity infrastructure by strengthening the public health workforce and surveillance systems. Key elements of these programmes enable their success and sustainability (Box) $[5,6]$.

FETPs fill an important gap by increasing the number of competent field epidemiologists, but the programmes go beyond training: the fellows also provide services needed by the host country, such as outbreak detection and response. Furthermore, and perhaps most importantly, the programmes contribute to the strengthening of the public health system as a whole. The majority of graduates stay within the public health system, and many take on positions of leadership, changing the culture to one of using data for decision making [6-8].

EPIET, the national FETPs, and the EPIET-associated programmes (where fellows from national programmes participate in the classroom training with the EPIET fellows) described here are part of a larger community of FETPs, linked together in a global

\section{B o x}

Key elements of field epidemiology training programmes

1. Competency-based curriculum

2. Mentorship by a senior field epidemiologist

3. Majority of participant's time spent in field and in service to host government priorities

host government priorities Recruitment and train
programme expands

5. Translation of data for evidence-based decision making

6. Programme initiates sustainability planning at an early stage network, the Training Programs in Epidemiology and Public Health Interventions Network (TEPHINET). Currently within TEPHINET there are 32 registered programmes (www.tephinet.org). Through partnerships with the host countries, the European Union (EU), the World Health Organization (WHO), TEPHINET, the United States Centers for Disease Control and Prevention (US CDC), multiple donors as well as private organisations, the number of FETPs continues to grow. The US CDC engage with 18 of these programmes outside Europe, providing a range of support from short-term technical assistance to placing a resident advisor from the US CDC within the ministry of health of the host government.

Within Europe, these applied epidemiology programmes are vigorously involved in public health surveillance and response activities, especially outbreak investigations. Bosman et al. report that EPIET and EPIET-associated programmes produced 340 publications in peer-reviewed journals over 12 years, all derived from fellowship projects [2]. Measuring FETPs' successes must take into account their intent to both train the next generation of public health leaders in epidemiology and to provide service and strengthen the health systems of their host governments. Success indicators such as number of graduates, field investigations, publications, and international missions are easier to obtain, while tracking career choices after graduation, number of graduates in leadership positions in public health, and their impact on policy decisions and public health systems are much harder to quantify.

Although the various programmes are linked in their approach to train epidemiologists, they use different models based on the respective country's needs and the programme's objectives. Krause et al. provide an overview of five national FETPs and compares them to EPIET [1]. The authors address a number of challenges related to retention and sustainability. For example, teaching in the native language in national FETPs assures that more of the most qualified and appropriate candidates can participate and may improve retention of the graduates in the country, but lack of English proficiency often limits the ability of the fellows to participate in activities in the international scientific community. Recruiting into the programmes from within the public health service may also improve retention, but may limit the ability to attract new, young scientists. Providing a university degree upon completion of the programme may enhance recruitment, retention, and opportunities for promotion in some countries, but may jeopardise the quantity and quality of field work if rigid university requirements reduce the availability of fellows for field activities. Sustainability relies 
heavily on the ability to retain graduates, as the programmes cannot be sustained or expanded unless fellows serve as mentors and supervisors after their graduation. Finally, the need to train more field epidemiologists is constantly threatened by funding and administrative issues.

It requires substantial resources to start and maintain an applied epidemiology training programme. Bosman et al. estimate that the EPIET programme costs between EUR 2.3 and 3.2 million per year for cohorts 8 through 11 [2]. Bremer et al. report that since the transition of EPIET to the ECDC in 2007, 84\% of the participants' salaries are funded by ECDC [3]. In the national FETPs, the country usually covers the costs of the participant's salary, since the participants are performing services for the government during their training. The majority of the costs are related to personnel required to supervise the participants and to supporting the introductory course and intermittent modular trainings.

Despite the relatively high costs, a demand for more qualified epidemiologists in Europe remains. Several articles appeal for the number of EPIET fellows to be increased, for strategies to facilitate return of these fellows to their country of origin, and creation of more FETP-like national programmes [3,4]. Krause et al. [4] suggest seconding an EU senior epidemiologist to new FETPs, much like the seconding of US CDC experts to the German and Italian FETPs. In some cases a regional approach might make sense. The cost of a national FETP in Europe is not presented, but the average cost of supporting a FETP by the US CDC is about USD 1 million per year, in the case where CDC remains fully engaged over a period of approximately five years. The costs decrease when the CDC resident advisor departs and the country takes over full responsibility for the programme.

Expanding the scale of FETPs within countries is another way of addressing the need for skilled epidemiologists. FETPs typically train 10 to 15 professionals in each cohort per year at the national level. Even with unlimited resources, there is an operational limit in the number of participants due to size of classrooms, number of supervisors and mentors, office space, etc. Having multiple FETPs within a country is an option, with each catering to different audiences. State-based FETP-like programmes exist in the US [9], and provincial FETPs are established in China. These programmes work together; for example, the national FETP in China sends fellows to the provinces for field experiences and the provinces ask the national FETP to assist with modular trainings. An annual scientific conference provides another opportunity for the provincial and national programmes to interact and learn from each other.

A key question is how many epidemiologists are needed. The Council of State and Territorial Epidemiologists (CSTE) in the US has recommended that the number of epidemiologists working in a state in the US be proportional to population size at the rate of at least one per 100,000 [10]. Based on this recommendation, the US currently has 30\% fewer epidemiologists than recommended, even though the Epidemic Intelligence Service (EIS) programme has produced more than 3,000 graduates since 1951 , with an additional 161 officers currently enrolled in the programme. Certainly not all epidemiologists working within a country need to go through FETP training. At different levels of the public health system, epidemiologists will need different skill sets. The Central America Regional FETP is an example of a comprehensive approach to training epidemiologists at multiple levels [8]. The curriculum is divided into a three-tiered training pyramid that corresponds to the needs at the local, district and central levels of the health system.
The articles in this special edition of Eurosurveillance disclose a vibrant network of applied epidemiology training programmes and epidemiology training activities, which are building public health workforce capacity in Europe. The health workforce is one of the six fundamental building blocks in the WHO health system framework [11], yet one of the greatest challenges to building effective public health systems globally continues to be the critical shortage of skilled public health workers [12]. Building sustainable health systems with a strong public health workforce and well-functioning surveillance and response systems will require commitment and support from all parts of the global public health community, based on the principles of the "Paris Declaration on Aid Effectiveness" calling for greater harmonisation of development resources [13]. By investing more strategically, donors and partner countries can not only achieve immediate impact through diseasespecific programmes, but also contribute to the strengthening and the long-term sustainability of the health system. Within the global epidemiology community, we have a responsibility to address the critical needs through strengthening international and regional networks, evaluating programmes, piloting innovative approaches, sharing experiences and lessons learned, and determining the most effective approaches to support further investment.

Graduates from applied epidemiology training programmes, such as the ones described in this special edition, will play leading roles in defining and addressing crucial health problems in their countries and the international community.

\section{References}

1. Krause G, Aavitsland P, Alpers K, Barrasa A, Bremer V, Helynck B, et al. Differences and Commonalities of National Field Epidemiology Training Programmes in Europe. Euro Surveill. 2009;14(43):pii=19378. Available from: http://www.eurosurveillance.org/ViewArticle.aspx?ArticleId $=19378$

2. Bosman A, Schimmer B, Coulombier D. Contribution of EPIET to public health workforce in the EU, 1995-2008. Euro Surveill. 2009;14(43):pij=19381. Available from: http://www.eurosurveillance.org/ViewArticle.aspx?ArticleId=19381

3. Bremer $V$, Bosman A, Coulombier D. New perspectives after the transition of EPIET to ECDC - the future of the programme. Euro Surveill. 2009;14(43):pii=19374. Available from: http://www.eurosurveillance.org/ ViewArticle.aspx?ArticleId $=19374$

4. Krause G, Stefanoff P, Moren A. Applied epidemiology training in Europe: quite a success - but more to be done. Euro Surveill. 2009;14(43):pii=19375. Available from: http://www.eurosurveillance.org/ViewArticle.aspx?ArticleId=19375

5. Nsubuga P, White M, Fontaine R, Simone P. Training programmes for field epidemiology. Lancet. 2008;371(9613):630-1.

6. White ME, McDonnell SM, Werker DH, Cardenas VM, Thacker SB. Partnerships in international applied epidemiology training and service, 1975-2001. Am J Epidemiol. 2001;154(11):993-9.

7. Jones DS, Tshimanga M, Woelk G, Nsubuga P, Sunderland NL, Hader SL, et al Increasing leadership capacity for HIV/AIDS programmes by strengthening public health epidemiology and management training in Zimbabwe. Hum Resour Health. 2009;7:69.

8. López A, Cáceres VM. Central America Field Epidemiology Training Program (CA FETP): a pathway to sustainable public health capacity development. Hum Resour Health. 2008;6:27.

9. Ragan P, Rowan A, Schulte J, Wiersma S. Florida Epidemic Intelligence Service Program: the first five years, 2001-2006. Public Health Rep. 2008;123 Suppl 1:21-7.

10. Boulton ML, Lemmings J, Beck AJ. Assessment of epidemiology capacity in state health departments, 2001-2006. J Public Health Manag Pract. 2009;15(4):328-36

11. World Health Organization. Everybody's business. Strengthening health systems to improve health outcomes. WHO's framework for action. Geneva: World Health Organization; 2007. Available from: http://www.wpro.who.int/NR/ rdonlyres/5BA80B95-DC1F-4427-8E8B-0D9B1E9AF776/0/EB.pdf

12. Chen L, Evans T, Anand S, Boufford JI, Brown H, Chowdhury M, et al. Human resources for health: overcoming the crisis. Lancet. 2004;364(9449):1984-90.

13. Paris declaration on aid effectiveness, ownership, harmonization, alignment, results, and mutual accountability. High Level Forum. Paris; Feb 28-Mar2 2005. Available from: http://www.oecd.org/dataoecd/11/41/34428351.pdf 